\title{
Influence of Urban Rail Transit on Corrosion of Buried Steel Gas Pipeline
}

\author{
Jianguo Feng, Zhiguang Chen, Yitong Xie, Cong Wu, Chaokui Qin* \\ Department of Mechanical and Energy Engineering, Tongji University, Shanghai 201804, China \\ *E-mail: chkqin@tongji.edu.cn.
}

doi: $10.20964 / 2021.06 .02$

Received: 26 January 2021 / Accepted: 20 March 2021 / Published: 30 April 2021

\begin{abstract}
It has been established that the operation of direct current (D.C.) rail traction systems can cause severe corrosion to neighbouring steel pipelines buried near rail buttresses. In this paper, a novel measurement device was developed to record the pipe-to-soil potential, surface potential gradient, and pipeline current of steel pipelines located in the vicinity of Shanghai rail transit line 1, Fujin Road Station. The results show that the pipe-to-soil potential fluctuated within $-2.04 \mathrm{~V} \sim 1.855 \mathrm{~V}$, the averaged surface potential gradient was $12.18 \mathrm{mV} / \mathrm{m}$, and its direction was 30.2 degrees southeast during rail transit operation. The current within the pipeline turned out to be $-40 \mathrm{~mA} 37 \mathrm{~mA}$ and the entering current is 4 times stronger than the leaving current. The comparison of measured data corresponding to periods of rail transit operation and no operation clearly revealed that the interference comes from rail traction. Finally, measures to mitigate this interference were proposed, including insulation joints, drainage devices, smart monitoring systems, etc. The work in this paper can therefore help protect the steel pipeline that was buried near the rail buttress from stray current corrosion during municipal construction processes.
\end{abstract}

Keywords: rail transit; rail buttress; pipeline corrosion; testing device; stray current

\section{$\underline{\text { FULL TEXT }}$}

(C) 2021 The Authors. Published by ESG (www.electrochemsci.org). This article is an open access article distributed under the terms and conditions of the Creative Commons Attribution license (http://creativecommons.org/licenses/by/4.0/). 